\title{
Enriched sera protein profiling for detection of non-small cell lung cancer biomarkers
}

\author{
Emanuela Monari ${ }^{1 *}$, Christian Casali ${ }^{2}$, Aurora Cuoghi ${ }^{1}$, Jessica Nesci ${ }^{2}$, Elisa Bellei ${ }^{1}$, Stefania Bergamini ${ }^{1}$, \\ Luca I Fantoni ${ }^{1}$, Pamela Natali ${ }^{2}$, Uliano Morandi ${ }^{2}$ and Aldo Tomasi ${ }^{1}$
}

\begin{abstract}
Background: Non Small Cell Lung Cancer (NSCLC) is the major cause of cancer related-death. Many patients receive diagnosis at advanced stage leading to a poor prognosis. At present, no satisfactory screening tests are available in clinical practice and the discovery and validation of new biomarkers is mandatory. Surface Enhanced Laser Desorption/Ionization Time-of-Flight Mass Spectrometry (SELDI-ToF-MS) is a recent high-throughput technique used to detect new tumour markers. In this study we performed SELDI-ToF-MS analysis on serum samples treated with the ProteoMinerTM kit, a combinatorial library of hexapeptide ligands coupled to beads, to reduce the wide dynamic range of protein concentration in the sample. Serum from 44 NSCLC patients and 19 healthy controls were analyzed with IMAC30-Cu and H50 ProteinChip Arrays.

Results: Comparing SELDI-TOF-MS protein profiles of NSCLC patients and healthy controls, 28 protein peaks were found significantly different $(p<0.05)$, and were used as predictors to build decision classification trees. This statistical analysis selected 10 protein peaks in the low-mass range $(2-24 \mathrm{kDa})$ and 6 in the high-mass range $(40-80$ $\mathrm{kDa})$. The classification models for the low-mass range had a sensitivity and specificity of $70.45 \%(31 / 44)$ and 68.42\% (13/19) for IMAC30-Cu, and 72.73\% (32/44) and 73.68\% (14/19) for H50 ProteinChip Arrays.

Conclusions: These preliminary results suggest that SELDI-ToF-MS protein profiling of serum samples pretreated with ProteoMinerTM can improve the discovery of protein peaks differentially expressed between NSCLC patients and healthy subjects, useful to build classification algorithms with high sensitivity and specificity. However, identification of the significantly different protein peaks needs further study in order to provide a better understanding of the biological nature of these potential biomarkers and their role in the underlying disease process.
\end{abstract}

\section{Background}

Lung cancer is the leading cause of cancer-related deaths worldwide [1]. More than $80 \%$ of lung cancer patients are affected by non small cell lung cancer (NSCLC), while the remaining $20 \%$ by small cell lung cancer (SCLC). Most of lung cancer cases are diagnosed in advanced stages, and only one third of patients with new diagnosis can undergo surgical treatment that, at present, is the therapeutic option associated to the best survival rate (5-ys $70 \%$ for Stage I after surgical resection). Many efforts have been made in the last decade to improve the percentage of diagnosis at early stage, as

\footnotetext{
* Correspondence: emanuela.monari@unimore.it

'Department of Laboratory Medicine, Medical Faculty, University of Modena and Reggio Emilia, Via del Pozzo 71, 41100, Modena, Italy

Full list of author information is available at the end of the article
}

both the chest radiography and the High Resolution Computed Tomography (HRCT) have proved to be inadequate screening tests [2]. Thus, is necessary to discover reliable biomarkers for an early and accurate diagnosis of the tumor condition.

Biomarker discovery in biological fluids, such as serum, plasma and urine, is one of the most challenging aspects of proteomic research. Most investigators believe that, due to heterogeneity of cancer diseases (histological grade, tumor stage, patient age, sex and genetic background), a set of biomarkers, instead of a single cancerspecific marker, might be more useful in clinical practice $[3,4]$.

Surface-Enhanced Laser Desorption/Ionization Timeof-Flight Mass Spectrometry (SELDI-ToF-MS) is a relatively new proteomic technology regarded as one of the

\section{Biomed Central}


most powerful tools for differential expression profiling. This is a high through-put technique that allows obtaining protein profiles from several complex biological samples, with minimal requirements for purification and separation, in a rapid and efficient way. Small amount of sample (such as body fluids or tissue cell lysate) is directly applied on biochips, available with different chromatographic surfaces (ProteinChip Arrays). Selectively retained proteins are then directly analyzed by laser desorption and ionization. The result is a mass spectrum comprised of the mass to charge $(\mathrm{m} / \mathrm{z})$ ratio and intensities of the bound peptide/protein [5]. Afterward, the statistical analysis of the obtained protein profiles permits to reveal any protein changes, with high sensitivity and specificity. One of the key feature of SELDI-ToF-MS analysis is its ability to detect a large number of low-molecular weight proteins $(<20 \mathrm{kDa})$, thus overcoming one of the major limitation of the twodimensional gel electrophoresis [6,7]. Furthermore, other mass spectrometry techniques (such as MALDI or ESI) may require pre-digestion of whole proteins with enzymes (for example trypsin) in order to generate peptides small enough to be analyzed. There are however drawbacks of SELDI-ToF-MS techniques such as competitive binding of high abundance non-informative proteins to the ProteinChip surfaces, and the need of a second step to identify the protein peaks of interest.

In the last years, this approach has been used to discover potential biomarkers for the diagnosis of some types of cancer, such as ovarian [8,9], breast [10,11], colorectal [12], and prostate cancer [13,14], as well as for many other diseases [4,15-18]. Recently, SELDI-ToF-MS profiling has been applied in a few studies aimed to identify lung cancer biomarkers analyzing tissue [19-22] and serum samples [23-28]. Unfortunately, although the obtained results are quite promising, so far none of the discovered biomarker has already been validated for the clinical use. It is well known that the discovery of protein biomarkers from serum samples is complicated due to its wide dynamic range (over 10 orders of magnitude). In addition, the few high-abundant blood species constitute $95 \%$ of the total protein content, representing, at the same time, less than $0.1 \%$ of the total proteins $[3,29]$, making very difficult the detection of the lowabundant components. The ProteoMiner ${ }^{\mathrm{TM}}$ technology is a novel approach, consisting of a combinatorial library of beads-coupled hexapeptide ligands, that assures the capture of all protein species present in a proteome enhancing the concentration of the most dilute ones [30-32]. The beads work on the principle of solid-phase affinity adsorption; each specie has theoretically the same probability to bind to its high affinity ligand. The most abundant proteins quickly saturated their binding sites, while the low and medium abundance proteins are concentrated on their specific ligands. At the end, only retained proteins are eluted and collected, while the excess proteins are washed away.

No depletion of any species is contemplated by this methodology, but a reduction of the relative concentration of the abundant components and a strong decrease of the sample dynamic range.

In this study, before investigating the proteomic profile of patients with NSCLC in comparison with healthy subjects, we treated serum samples with the ProteoMinerTM kit. Our goal was to verify, by SELDI-ToF-MS analysis, the presence of specific protein patterns in enriched serum samples, able to discriminate NSCLC patients from healthy subjects.

\section{Methods}

\section{Study population and clinical specimens}

Whole blood samples $(10 \mathrm{~mL})$ were collected immediately before surgery in a test tube and allowed to clot at room temperature for $1 \mathrm{~h}$. After centrifugation at 2000 $\times \mathrm{g}$ for $10 \mathrm{~min}$ at $4^{\circ} \mathrm{C}$, serum was divided in aliquots and immediately stored at $-80^{\circ} \mathrm{C}$ until use.

Serum samples from 44 NSCLC patients and 19 from healthy subjects were analyzed.

All NSCLC cases were candidate to complete surgical resection. Moreover, no patient underwent induction chemotherapy before surgery. The histological distribution was: 28 adenocarcinomas and 16 squamous carcinomas (histological diagnosis according to the World Health Organization 2004 classification of lung tumors). Patients were staged according to the new 2009 IASLC (International Association for the Study of Lung Cancer) staging system. Pathologic stage distribution was as follows: 15 stage IA, 12 stage IB, 5 stage IIA, 4 stage IIB, 7 stage IIIA, and 1 stage IIIB (multiple nodules in different lobes). The mean age was 71 years, (range 51-88 years, STD 8 years); 9 female and 35 males. Nineteen healthy volunteers were selected as controls; the mean age was 68 years; range 47-82 years, STD 10 years, 4 females and 13 males (no statistical difference was present between cases and control regarding gender and age). The main inclusion criteria for this group was the absence of pulmonary diseases proved by a recent chest $\mathrm{X}$-Ray. The present study was performed according to a protocol approved by the Ethical Committee of the University Hospital of Modena, Italy. Voluntary informed consent to donate serum was obtained for all research participants.

\section{Protein enrichment}

ProteoMiner ${ }^{\mathrm{TM}}$ Protein Enrichment kit (BioRad Laboratories Inc., Hercules, CA, USA) was utilized according to the manufacturer instructions. Briefly, $1 \mathrm{~mL}$ of serum was added to spin columns containing the beads and 
incubated at room temperature for $2 \mathrm{~h}$ with constant end-to-end rotation. After columns wash, the proteins bound to the beads were eluted with the appropriate buffer, divided in aliquots and stored at $-20^{\circ} \mathrm{C}$ until use. In order to obtain a quality control (QC) sample as similar as possible to the analyzed samples, $20 \mu \mathrm{L}$ of each sample treated with the ProteoMiner ${ }^{\mathrm{TM}}$ kit were pooled and used for all the experiments. Protein concentration of each sample was assessed using an assay based on the Bradford method [33].

\section{SELDI-ToF-MS protein profiling}

Enriched serum samples were analyzed with SELDIToF-MS, with the purpose to investigate the protein profile in both the low $(2-30 \mathrm{kDa})$ and the high (30-100 $\mathrm{kDa})$ molecular weights $(\mathrm{MW})$. In a preliminary study, in order to set up the experimental conditions, pooled serum samples were loaded onto three different types of ProteinChip Arrays (Bio-Rad Laboratories Inc., Hercules, CA, USA): H50 (that binds proteins through reversephase or hydrophobic interactions), CM10 (negatively charged surface that acts as a weak cation-exchanger) and IMAC30-Cu (Immobilized Metal Affinity Capture surface pre-activated with copper). The CM10 array gave the lower number of peaks detected $(\sim$ less than $10 \%)$ and the lower total signal intensity ( less than $50 \%$ ) compared to $\mathrm{H} 50$ and IMAC $30-\mathrm{Cu}$, so only these two arrays were used in the main study.

In order to minimize any bias sources, each sample was randomly loaded in duplicate in a 96 well bioprocessor. Moreover, to assess the reproducibility, a QC sample was included in each ProteinChip array and all steps were automated using a robotic instrument for liquid handling (Biomek 3000 Laboratory Automation Workstation, Beckman Coulter, Fullerton, CA, USA).

Ten microliters of diluted serum sample $(3 \mu \mathrm{g} / \mu \mathrm{L}$ final concentration) were mixed with $90 \mu \mathrm{L}$ of binding buffer and loaded onto pre-equilibrated ProteinChip Array spot surfaces. After $45 \mathrm{~min}$ incubation at room temperature with constant horizontal shaking, the unbound proteins were removed by three washing steps using $200 \mu \mathrm{L}$ of the same binding buffer. Finally, $1 \mu \mathrm{L}$ of saturated sinapinic acid solution in $0.5 \%$ trifluoroacetic acid and $50 \%$ acetonitrile (Sigma-Aldrich, St.Louis, MO, USA) was applied to each spot twice, allowing the surface to dry between each application.

\section{Data acquisition}

The ProteinChip Arrays were analyzed with a SELDIToF-MS reader (Series 4000, Bio-Rad Laboratories Inc., Hercules, CA, USA), by protocols optimized for low and high MW ranges. Protein mass spectra were generated using an average of 901 laser shot for each protocol. The "All-in-one protein standard II" (Bio-Rad
Laboratories Inc., Hercules, CA, USA) was used to obtain protein standard spectra for mass accuracy calibration.

\section{Statistical analysis}

Statistical analysis was performed using the ProteinChip Data Manager 3.0 software (Bio-Rad Laboratories Inc., Hercules, CA, USA). The spectra were mass calibrated, baseline subtracted, mass aligned and finally normalized by total ion current in both the MW ranges of interest. All poor quality spectra were excluded from the statistical analysis. Supervised clustering was performed using the following settings: 5 times signal-to-noise $(\mathrm{S} / \mathrm{N})$ ratio and $20 \%$ min peak threshold in the first pass for peaks identification, and 2 times $\mathrm{S} / \mathrm{N}$ ratio on the second pass for cluster completion.

After clusters identification, to test the null hypothesis that the medians of peak intensities of the two groups were equal, Mann Whitney $\underline{\mathrm{U}}$ test was performed. A pvalue less than 0.05 was accepted as statistically significant.

To test the overall quality of the assay, QC sample spectra replicates were used to calculate pooled CV\%. This was obtained, for each protocol, using the intensity $\mathrm{CV} \%$ of 20 representative cluster peaks, regularly distributed for mass ranges and peak intensities, including all the statistical significant peaks. The pooled CV \% means were $23.4 \%$ and $24.5 \%$ in the low-mass range, and $22.2 \%$ and $24.1 \%$ in the high- mass range, for IMAC30-Cu and $\mathrm{H} 50$, respectively.

\section{Decision tree classification}

Decision tree classification was performed using Biomarker Pattern Software 5.0 (Ciphergen, USA) based on CART (Classification And Regression Trees) as described by Breiman et al. [34]. Classification tree split up a data set into nodes using one rule at a time. For each node the decision is made by the presence or absence or the intensity level of one peak until a terminal node is reached or further splitting has no gains. Classification was performed using as target the group (class), the Gini method, and 10-fold cross-validation, and as predictors all the peaks with a statistical significance between NSCLC and controls (p-value $<0.05$ ). Peaks selected by this process are the ones present in the lowest cost trees. The 10-fold cross- validation test divided the data set into approximately 10 equal subsets. The tree-growing process is repeated from scratch 10 times and in each cross-validation replication nine subsets of the data are used as learning data and one subset is used as a test sample. At the end of process, the error counts from each of the 10 test samples are summed to obtain the overall error count for each tree in the fullsample tree sequence. 


\section{Results}

A total of 63 enriched serum samples were analyzed by SELDI-ToF-MS with both IMAC30- $\mathrm{Cu}$ and H50 ProteinChip Arrays. For each reading protocol, the MS spectra were processed as described above. A total of 106 cluster peaks (88 in the low- and 18 in the highMW) for IMAC30-Cu, and 95 peaks (73 in the low- and 22 in the high-MW) for H50 were detected. Non-parametric Mann-Witney U test was carried out to verify the presence of peaks with statistically significant relative intensities between NSCLC patients and control subjects. Using IMAC30-Cu, 9 significant peaks (6 in the low-MW range and 3 in the high-MW range) were found comparing NSCLC patients to controls. With H50 ProteinChip Array, 19 significant peaks (14 in the low-MW and 5 in the high-MW) were obtained. These differentially expressed peaks (Additional file 1, Table S1) were used to construct decision trees classification algorithms, in the attempt to identify potential serum biomarkers for NSCLC.

For IMAC30-Cu, 6 statistically different protein peaks in the low-MW range were chosen as predictor to build up the decision classification tree shown in Figure 1. The classification algorithm used 4 protein peaks and 6 terminal node were determined with a relative cost of 0.61 . The accuracy of this algorithm was $93.65 \%(59 / 63)$, which correctly classified 41 of 44 NSCLC (93.18\%) and 18 of 19 healthy controls $(94.74 \%)$. The accuracy after 10 -fold cross-validation was $69.84 \%$, with sensitivity of $70.45 \%(31 / 44)$ and specificity of $68.42 \%(13 / 19)$. In Table 1 are listed the 4 protein peaks: 3 were up-regulated $(2664,4466,8934 \mathrm{~m} / \mathrm{z})$, and 1 was down-regulated $(12451 \mathrm{~m} / \mathrm{z})$ in NSCLC patients. Figure 2 shows representative spectra of these protein peaks in NSCLC patients and controls.

The same analysis was carried out with H50 ProteinChip Array, using as predictors 14 significant peaks found in the low-MW range; the classification algorithm selected 5 protein peaks, reported in Table 2 . Three of these peaks were up-regulated $(9365,9712$, and 23972 $\mathrm{m} / \mathrm{z}$ ) and 2 were down-regulated (7612 and $12455 \mathrm{~m} / \mathrm{z}$ ) in NSCLC patients compared with controls. Representative spectra are shown in Figure 3. The classification decision tree generated 6 terminal nodes with a relative cost of 0.536 (Figure 4). The decision algorithm correctly classified 42 of 44 NSCLC patients (95.45\%) and 18 of 19 controls (94.74\%), with an accuracy of $95.23 \%$ $(60 / 63)$. After crossing validation, the accuracy decreased to $73.01 \%(46 / 63)$ with sensitivity of $72.73 \%$ $(32 / 44)$ and specificity of $73.68 \%(14 / 19)$.

Decision classification trees were also obtained using as predictors the statistically significant peaks detected in the high-mass range $(30-100 \mathrm{kDa})$ for IMAC30-Cu (Additional File 2, Figure S1) and H50 (Additional File
3, Figure S2). Two peaks were selected by this process for IMAC30- $\mathrm{Cu}$ and 3 peaks for $\mathrm{H} 50$, respectively (Table 3 ). In this case, the relative cost and the misclassification rate were higher than those obtained in the low-MW. Actually, after 10-fold-cross-validation, 31 of 44 NSCLC patients (70.45\%) and 6 of 19 control subjects (68.42\%) using IMAC30-Cu, and 21/44 NSCLC (47.73\%) and 9 of 19 (52.63\%) controls with H50 ProteinChip Arrays, were correctly classified.

Finally, all the 28 statistically significant peaks, identified in all experimental condition, were used as predictors to build an unique decision classification tree (Additional File 4, Figure S3). This algorithm used 5 protein peaks: 3 already selected in other decision algorithms (7612, 8934 and $12455 \mathrm{~m} / \mathrm{z}$ ) and 2 new peaks (12588 and $44689 \mathrm{~m} / \mathrm{z}$ ) (Additional File 5, Table S2).

The decision algorithm correctly classified 40 of 44 NSCLC patients (90.91\%) and 18 of 19 controls (94.74\%), with an accuracy of $92.06 \%$ (58/63). After crossing validation, the accuracy decreased to $61.90 \%$ $(39 / 63)$ with sensitivity of $65.91 \%(29 / 44)$ and specificity of $52.63 \%(10 / 19)$.

\section{Discussion}

The incidence of lung cancer is constantly increasing, with an high mortality rate due to delay in diagnosis. For this reason, early NSCLC biomarkers could be crucial for the diagnosis, prognosis and follow-up. Many studies have been made in the past years in the attempt to discover reliable biomarkers, but, to date, their poor organ and tumor specificity limits their use to prognosis and therapy monitoring [35].

In order to discover novel protein biomarkers, a number of different technologies are used. Among these techniques, SELDI has the advantage to allow direct protein profiles of biological fluids (such as serum or urine) in a rapid and reproducible way. This generate an huge amount of data that can be directly analyzed with the bioinformatics tools coupled with the system.

Although this technology was successfully applied for the discovery of candidate biomarker in different tumor types, currently, in literature, only few SELDI-ToF-MS studies on lung cancer are reported, especially performed on crude serum samples, without any preliminary pre-fractionation or depletion treatment. For example, Han et al. [26] analyzed, on H4 ProteinChip Array, untreated serum from patients with SCLC, NSCLC, pneumonia and from healthy individuals, defining 3 different protein patterns able to discriminate SCLC from controls and the different diseases with each other. Some authors used CM10 ProteinChip Array to compare crude serum of lung cancer patients and healthy controls. Although the same ProteinChip type was used, they discovered different protein peaks, 


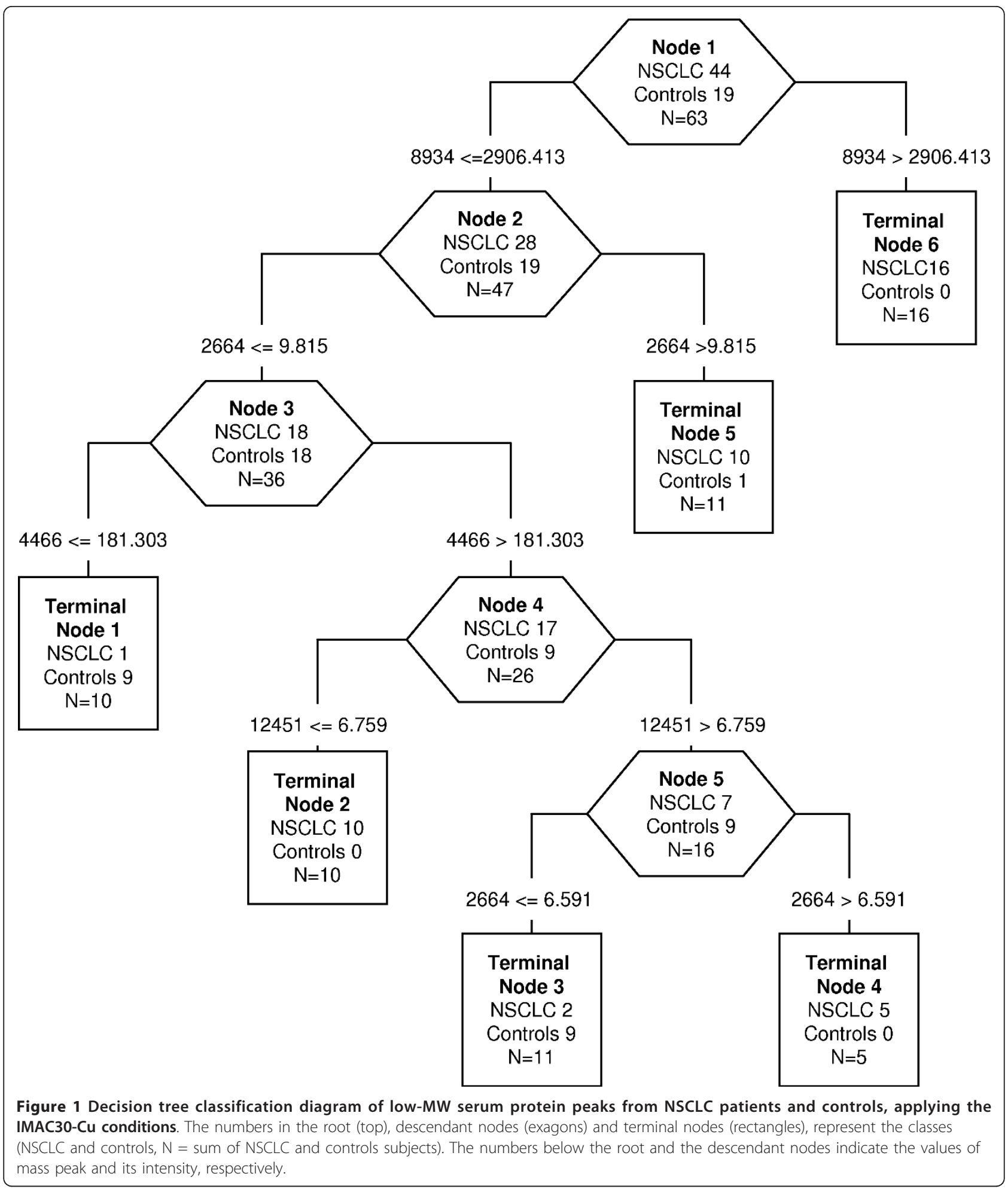

proposed as candidate biomarkers. Dai et al, in fact, identified a protein peak at $11.6 \mathrm{kDa}$ (serum Amyloid A protein), able to discriminate lung cancers from controls with a sensitivity of $84 \%$ and specificity of $80 \%$ [25]. Yang et al. [23] detected 5 protein peaks at $\mathrm{m} / \mathrm{z} 11493$,
$6429,8345,5335$ and 2538 that were chosen to build a classification algorithm. It permitted to discriminate stages I and II of NSCLC with a sensitivity of $91.4 \%$ and $79.1 \%$, respectively. More recently, Yang et al. [28] discovered and validate 3 candidate biomarkers in NSCLC: 
Table 1 Comparison of low-MW predictor protein peaks intensities (IMAC30-Cu) between NSCLC patients and controls

\begin{tabular}{|c|c|c|c|c|c|c|c|}
\hline \multirow{2}{*}{$\begin{array}{c}\mathrm{m} / \mathrm{z} \\
2664\end{array}$} & \multicolumn{3}{|c|}{$\begin{array}{c}\text { NSCLC } \\
(\text { mean } \pm \text { SD })\end{array}$} & \multicolumn{3}{|c|}{$\begin{array}{c}\text { Controls } \\
(\text { mean } \pm S D)\end{array}$} & \multirow{2}{*}{$\begin{array}{c}\text { p-value } \\
0.020\end{array}$} \\
\hline & 8.672 & \pm & 4.215 & 6.142 & \pm & 2.948 & \\
\hline 4466 & 234.807 & \pm & 56.203 & 195.299 & \pm & 63.867 & 0.046 \\
\hline 8934 & 2503.941 & \pm & 516.768 & 2303.279 & \pm & 247.386 & 0.022 \\
\hline 12451 & 4.182 & \pm & 3.304 & 6.471 & \pm & 4.294 & 0.036 \\
\hline
\end{tabular}

Table 2 Comparison of low-MW predictor protein peaks intensities ( $\mathrm{H} 50)$ between NSCLC patients and controls

\begin{tabular}{cccccccc}
\hline $\mathbf{m} / \mathbf{z}$ & \multicolumn{3}{c}{$\begin{array}{c}\text { NSCLC } \\
\text { (mean } \pm \text { SD) }\end{array}$} & \multicolumn{3}{c}{$\begin{array}{c}\text { Controls } \\
\text { (mean } \pm \text { SD) }\end{array}$} & p-value \\
\hline 7612 & 1.051 & \pm & 0.681 & 1.847 & \pm & 0.836 & 0.001 \\
9365 & 4.269 & \pm & 1.403 & 3.353 & \pm & 0.871 & 0.019 \\
9712 & 3.764 & \pm & 2.797 & 1.919 & \pm & 0.518 & 0.002 \\
12455 & 0.702 & \pm & 0.674 & 0.886 & \pm & 0.483 & 0.019 \\
23972 & 0.064 & \pm & 0.025 & 0.052 & \pm & 0.033 & 0.030 \\
\hline
\end{tabular}
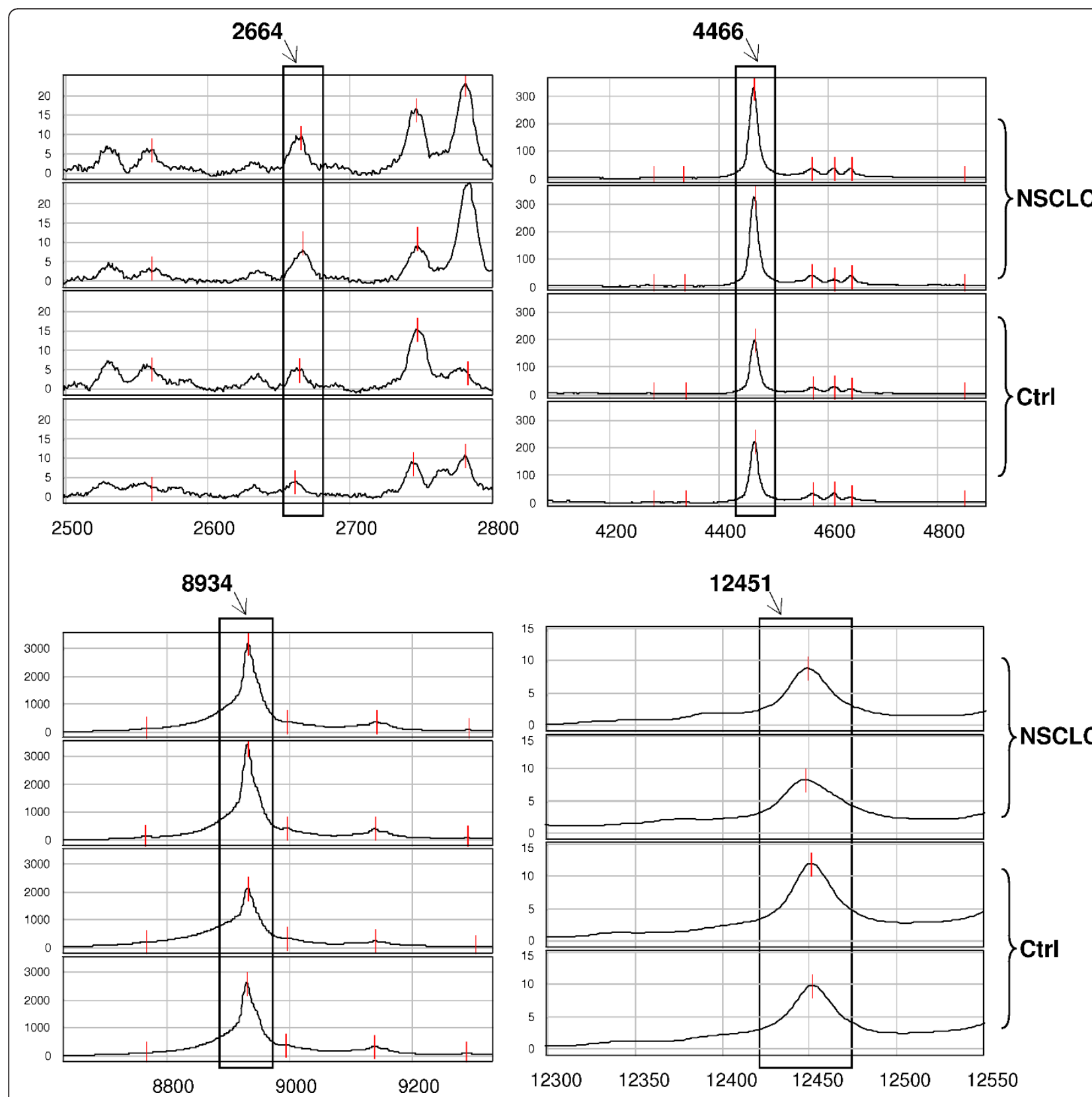

Figure 2 Serum protein profile of low-MW predictor peaks (IMAC30-Cu). Representative spectra (in duplicate) obtained by SELDI-ToF-MS analysis concerning the 4 statistically significant peaks detected with IMAC30-Cu and used as predictors to build the decision classification tree shown in Figure 1. The peaks of interest are highlighted in rectangles and their $\mathrm{m} / \mathrm{z}$ values are reported above. (Ctrl $=$ control subjects). 


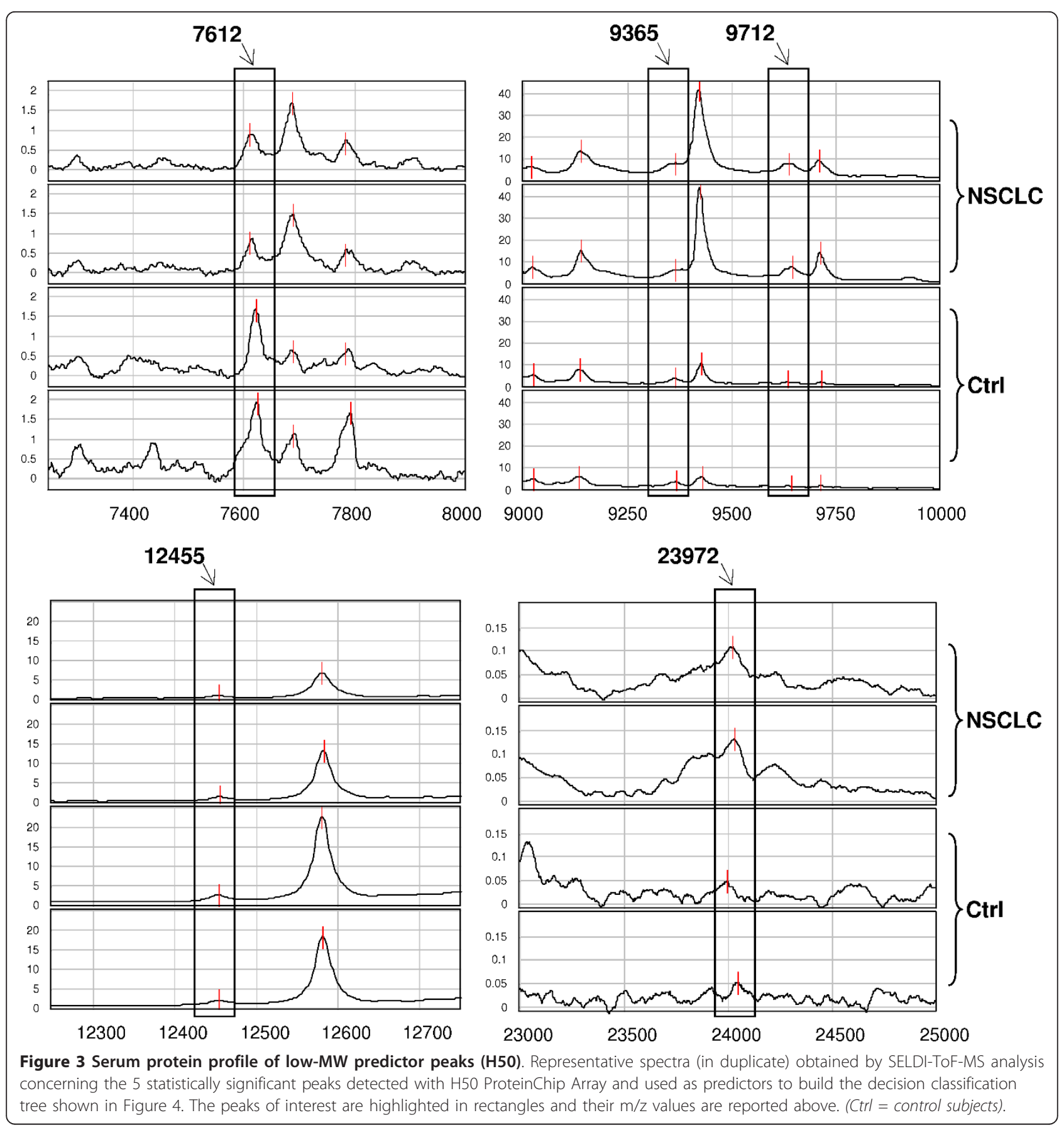

one down-regulated, identified as apolipoprotein C-I $(6628 \mathrm{Da})$, and 2 up-regulated, haptoglobin alpha-1 chain $(9191 \mathrm{Da})$ and S100A4 (11412 Da). Moreover, other ProteinChip Arrays, such as IMAC-30, were used to perform SELDI-ToF analysis on crude serum samples from lung cancer patients [27].

The only work on pretreated serum samples is by $\mathrm{Au}$ et al. [24]: they used the Equalizer beads, the developing combinatorial library ligands technology that was then commercialized with the trade name ProteoMiner. They treated serum from never-smoked lung cancer patients and normal control subjects using IMAC30 and Q10 ProteinChip Array. Comparing the serum proteomic profiles of patients with controls, they found several statistically significant protein peaks, mostly in the high mass-range ( $>50 \mathrm{kDa})$.

Unlike the majority of the previous studies reported in literature, we conducted a SELDI-ToF-MS analysis on 


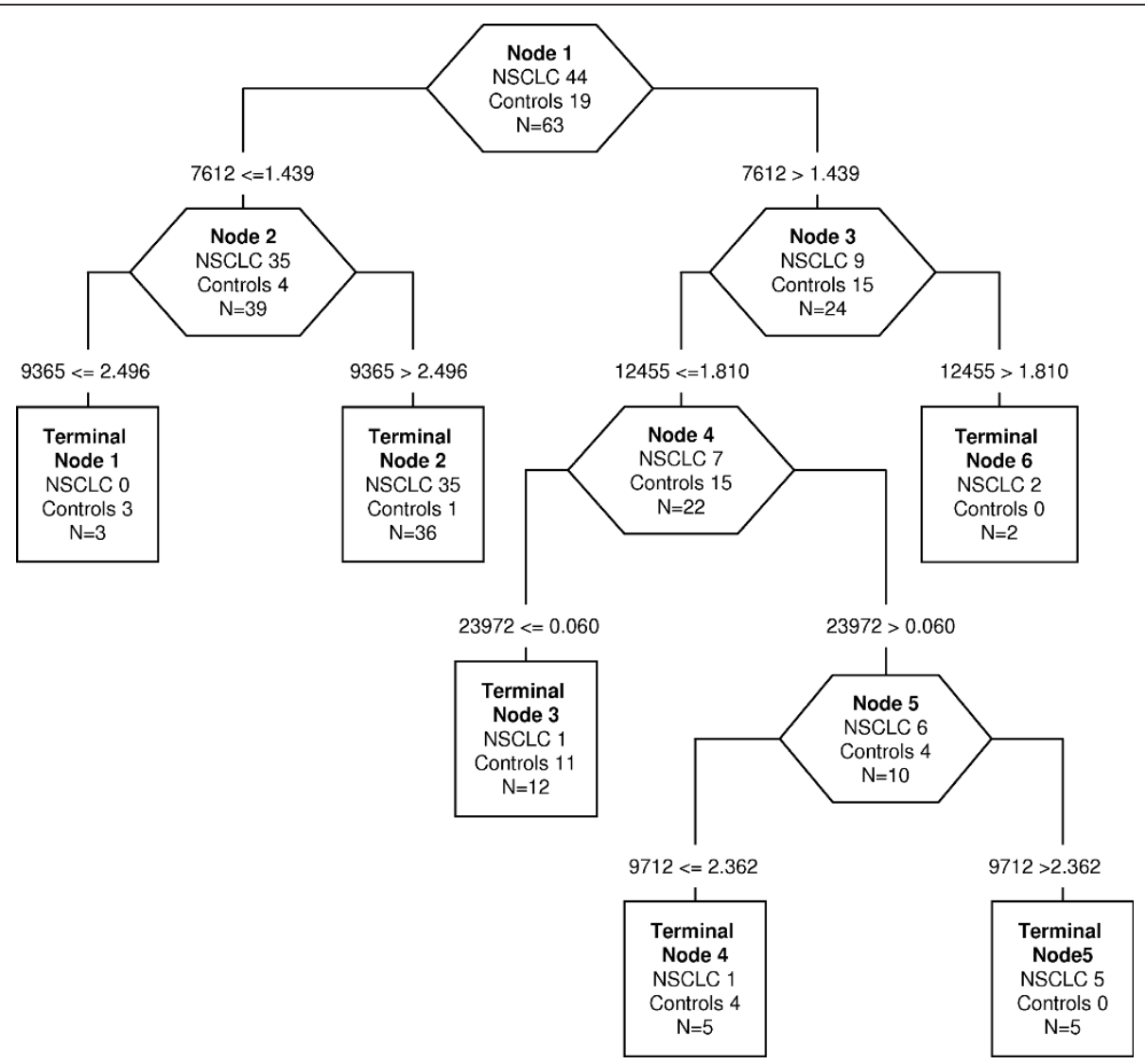

Figure 4 Decision tree classification diagram of low-MW protein peaks from NSCLC patients and controls, using H50 conditions. The numbers in the root (top), descendant nodes (exagons) and terminal nodes (rectangles), represent the classes (NSCLC patients and controls, $\mathrm{N}=$ sum of NSCLC and controls). The numbers below the root and descendant nodes indicate the values of mass peak and its intensity, respectively.

serum samples treated with commercially available ProteoMiner ${ }^{\mathrm{TM}}$ kit. This technique has the main advantage to reduce the serum high dynamic range by lowering the concentration of most abundant protein species and simultaneously concentrating the less abundant ones. Other different depletion methods, based on dye-ligands or specific antibodies, are currently available but they could produce some drawbacks, such as co-depletion

Table 3 Comparison of high-MW range predictor peak intensities between NSCLC patients and controls for IMAC30-Cu and H50

\begin{tabular}{lllllllll}
\hline $\mathbf{m} / \mathbf{z}$ & \multicolumn{3}{c}{$\begin{array}{c}\text { NSCLC } \\
\text { (mean } \pm \text { SD) }\end{array}$} & \multicolumn{3}{c}{$\begin{array}{c}\text { Controls } \\
\text { (mean } \pm \text { SD) }\end{array}$} & p-value \\
\hline $\begin{array}{llllllllll}\text { IMAC30-Cu } \\
45973\end{array}$ & 1.514 & \pm & 0.448 & 1.097 & \pm & 0.331 & 0.001 \\
80313 & 0.134 & \pm & 0.073 & 0.172 & \pm & 0.094 & 0.050 \\
\hline $\mathbf{H 5 0}$ & & & & & & & \\
34527 & 2.346 & \pm & 0.569 & 2.039 & \pm & 0.497 & 0.036 \\
51996 & 0.327 & \pm & 0.326 & 0.255 & \pm & 0.338 & 0.026 \\
73503 & 0.128 & \pm & 0.010 & 0.066 & \pm & 0.031 & 0.025 \\
\hline
\end{tabular}

[36]. It is widely demonstrated that the ProteoMiner ${ }^{\mathrm{TM}}$ technique is able to increase the recovery yield of protein species detected with two-dimensional gel electrophoresis and SELDI-ToF-MS analysis, preserving their proportionality. This permits to reveal low and medium abundance proteins in serum and plasma samples, as needed for biomarker discovery [37-39].

In the present work we treated with this new approach serum samples from 44 NCSLC and 19 healthy controls, obtaining 106 cluster of protein peaks for IMAC30-Cu and 95 for H50 ProteinChip Arrays, respectively. The comparison of the clusters between the two group identified 28 cluster peaks (20 in the low and 8 in the high mass range) statistically different ( $<<$ 0.05 ) and they were used as predictors to build decision classification algorithms (4 classifications built considering ProteinChip type and MW separately, and 1 built considering all conditions). These analyses selected 4 peaks in the low- and 2 peaks in the high-MW for IMAC30- $\mathrm{Cu}$, and 5 in the low- and 3 in the high-MW for H50. The classification models for the low-mass range after 10 -fold cross-validation had a sensitivity of 
$70.45 \%(31 / 44)$ and a specificity of $68.42 \%(13 / 19)$ for IMAC30-Cu, and $72.73 \%(32 / 44)$ sensitivity and $73.68 \%$ (14/19) specificity for H50 ProteinChip Array. The classification algorithm built with all cluster identified in all experimental conditions allowed to single out two more peaks, even if this algorithm had a lower classification power, $65.91 \%(29 / 44)$ sensitivity and 52,63\% (10/19) specificity.

When compared with other studies present in literature, the use of ProteoMiner ${ }^{\mathrm{TM}}$ kit permits to increase the number of significant peaks able to discriminate NSCLC patients from healthy controls. In fact, although the limited number of enrolled subjects and considering the relatively heterogeneity of cases regarding disease stage, a total of 16 interesting protein peaks were discovered, mostly in the low mass range. It is also important to note that all cases enrolled came from a surgical series and all patients with a clearly metastatic disease (stage IV) were excluded. This point addresses the possibility to discover potential candidate biomarkers to differentiate patients amenable of a surgical treatment at diagnosis, that is the therapeutic option associated to the best survival rate.

\section{Conclusions}

In summary, in our study we used the ProteoMiner ${ }^{\mathrm{TM}}$ kit prior to SELDI-ToF-MS analysis to reduce the complexity of NSCLC and controls serum samples. Statistical analysis of differentially expressed protein peaks has permitted to build algorithms, that could discriminate between NSCLC patients and control subjects, with high rate of sensitivity and specificity. Our results show that the SELDI-ToF-MS technology coupled with the ProteoMiner ${ }^{\mathrm{TM}}$ strategy is able to identify a set of protein peaks as candidate biomarkers, in a rapid and high-throughput mode. These protein peaks could be useful to select, among patients at risk to develop lung cancer (such as heavy smokers $>40$ years), those that require an aggressive radiological follow up, in order to discover the neoplastic condition at an early stage. However, further studies, increasing the number of patients and controls, are needed to confirm these results and especially to identify and subsequently validate the discovered protein peaks.

\section{Additional material}

Additional file 1: Table S1 -Comparison of mass peak intensities between NSCLC and Controls.

Additional file 2: Figure S1- Diagram of the decision tree classification of serum protein peaks between NSCLC and Controls in IMAC30-Cu high-mass range condition.

Additional file 3: Figure S2 - Diagram of the decision tree classification of serum protein peaks between NSCLC and Controls in $\mathrm{H} 50$ high-mass range condition.
Additional file 4: Figure S3 - Diagram of the decision tree classification for all significant protein peaks between NSCLC and Controls.

Additional file 5: Table S2 -Comparison of mass peak intensities between NSCLC and Controls.

\section{List of abbreviations}

NSCLC: Non Small Cell Lung Cancer; SCLC: small cell lung cancer; SELDI-ToFMS: Surface Enhanced Laser Desorption/lonization Time-of-Flight mass spectrometry.

\section{Acknowledgements}

This work has been supported by Fondazione Cassa di Risparmio di Vignola and by Fondazione Cassa di Risparmio di Modena, Modena, Italy.

\section{Author details}

${ }^{1}$ Department of Laboratory Medicine, Medical Faculty, University of Modena and Reggio Emilia, Via del Pozzo 71, 41100, Modena, Italy. ${ }^{2}$ Division of Thoracic Surgery, Department of General Surgery and Surgical Specialties, University of Modena and Reggio Emilia, Via del Pozzo 71, 41100, Modena, Italy.

\section{Authors' contributions}

EM performed proteomics experiments and wrote the manuscript, CC, JN and PN selected clinical cases and collected serum samples, AC and EB performed proteomics experiments, SB and LIF carried out samples preparation for mass spectrometry analysis, UM and AT supervised the work, provided useful suggestions to improve performance, and revised the manuscript.

All authors have seen a draft copy of the manuscript and agree with its publication.

\section{Competing interests}

The authors declare that they have no competing interests.

Received: 28 March 2011 Accepted: 19 September 2011 Published: 19 September 2011

\section{References}

1. Jemal A, Center MM, DeSantis C, Ward EM: Global patterns of cancer incidence and mortality rates and trends. Cancer Epidemiol Biomarkers Prev 2010, 19:1893-1907.

2. Bach PB, Jett JR, Pastorino U, Tockman MS, Swensen SJ, Begg CB: Computed tomography screening and lung cancer outcomes. Jama 2007, 297:953-961.

3. Petricoin EF, Belluco C, Araujo RP, Liotta LA: The blood peptidome: a higher dimension of information content for cancer biomarker discovery. Nat Rev Cancer 2006, 6:961-967.

4. De Bock M, de Seny D, Meuwis MA, Chapelle JP, Louis E, Malaise M, Merville MP, Fillet M: Challenges for Biomarker Discovery in Body Fluids Using SELDI-TOF-MS. J Biomed Biotechnol 2010.

5. Hutchens TW, Yip TT: New Desorption Strategies for the MassSpectrometric Analysis of Macromolecules. Rapid Commun Mass Sp 1993, 7:576-580.

6. Wright GL Jr: SELDI proteinchip MS: a platform for biomarker discovery and cancer diagnosis. Expert Rev Mol Diagn 2002, 2:549-563.

7. Tang N, Tornatore P, Weinberger SR: Current developments in SELDI affinity technology. Mass Spectrom Rev 2004, 23:34-44.

8. Petricoin EF, Ardekani AM, Hitt BA, Levine PJ, Fusaro VA, Steinberg SM, Mills GB, Simone C, Fishman DA, Kohn EC, Liotta LA: Use of proteomic patterns in serum to identify ovarian cancer. Lancet 2002, 359:572-577.

9. Moore LE, Fung ET, McGuire M, Rabkin CC, Molinaro A, Wang Z, Zhang F, Wang J, Yip C, Meng XY, Pfeiffer RM: Evaluation of apolipoprotein A1 and posttranslationally modified forms of transthyretin as biomarkers for ovarian cancer detection in an independent study population. Cancer Epidemiol Biomarkers Prev 2006, 15:1641-1646.

10. Clarke CH, Buckley JA, Fung ET: SELDI-TOF-MS proteomics of breast cancer. Clin Chem Lab Med 2005, 43:1314-1320. 
11. Leong S, Christopherson Rl, Baxter RC: Profiling of apoptotic changes in human breast cancer cells using SELDI-TOF mass spectrometry. Cell Physiol Biochem 2007, 20:579-590.

12. Liu M, Li CF, Chen HS, Lin LQ, Zhang CP, Zhao JL, Liu Y, Zhang SJ, Jin JC, Wang L, Liu JR: Differential expression of proteomics models of colorectal cancer, colorectal benign disease and healthy controls. Proteome Sci 2010, 8:16.

13. Adam BL, Qu YS, Davis JW, Ward MD, Clements MA, Cazares LH, Semmes OJ, Schellhammer PF, Yasui Y, Feng ZD, Wright GL: Serum protein fingerprinting coupled with a pattern-matching algorithm distinguishes prostate cancer from benign prostate hyperplasia and healthy men. Cancer Res 2002, 62:3609-3614.

14. Semmes OJ, Feng Z, Adam BL, Banez LL, Bigbee WL, Campos D, Cazares LH, Chan DW, Grizzle WE, Izbicka E, et al: Evaluation of serum protein profiling by surface-enhanced laser desorption/ionization timeof-flight mass spectrometry for the detection of prostate cancer: I. Assessment of platform reproducibility. Clin Chem 2005, 51:102-112.

15. Bons JA, van Dieijen-Visser MP, Wodzig WK: Clinical proteomics in chronic inflammatory diseases: A review. Proteomics Clin Appl 2007, 1:1123-1133.

16. Hodgetts A, Levin M, Kroll JS, Langford PR: Biomarker discovery in infectious diseases using SELDI. Future Microbiol 2007, 2:35-49.

17. Martinez-Pinna R, Martin-Ventura JL, Mas S, Blanco-Colio LM, Tunon J, Egido J: Proteomics in atherosclerosis. Curr Atheroscler Rep 2008, 10:209-215.

18. Whelan LC, Power KA, McDowell DT, Kennedy J, Gallagher WM: Applications of SELDI-MS technology in oncology. J Cell Mol Med 2008, 12:1535-1547.

19. Yang S, Nan Y, Tian Y, Zhang W, Zhou B, Bu L, Huo S, Chen G, Yu J, Zheng S: Study of distinct protein profiles for early diagnosis of NSCLC using LCM and SELDI-TOF-MS. Med Oncol 2008, 25:380-386.

20. Zhukov TA, Johanson RA, Cantor AB, Clark RA, Tockman MS: Discovery of distinct protein profiles specific for lung tumors and pre-malignant lung lesions by SELDI mass spectrometry. Lung Cancer 2003, 40:267-279.

21. Au JS, Cho WC, Yip TT, Law SC: Proteomic approach to biomarker discovery in cancer tissue from lung adenocarcinoma among nonsmoking Chinese women in Hong Kong. Cancer Invest 2008, 26:128-135.

22. Bouamrani A, Ternier J, Ratel D, Benabid AL, Issartel JP, Brambilla E, Berger F: Direct-tissue SELDI-TOF mass spectrometry analysis: a new application for clinical proteomics. Clin Chem 2006, 52:2103-2106.

23. Yang SY, Xiao XY, Zhang WG, Zhang L, Zhang W, Zhou B, Chen G, He DC: Application of serum SELDI proteomic patterns in diagnosis of lung cancer. BMC Cancer 2005, 5:83.

24. Au JS, Cho WC, Yip TT, Yip C, Zhu H, Leung WW, Tsui PY, Kwok DL, Kwan SS, Cheng WW, et al: Deep proteome profiling of sera from neversmoked lung cancer patients. Biomed Pharmacother 2007, 61:570-577.

25. Dai S, Wang X, Liu L, Liu J, Wu S, Huang L, Xiao X, He D: Discovery and identification of Serum Amyloid A protein elevated in lung cancer serum. Sci China C Life Sci 2007, 50:305-311.

26. Han M, Liu Q, Yu J, Zheng S: Detection and significance of serum protein markers of small-cell lung cancer. J Clin Lab Anal 2008, 22:131-137.

27. Han $\mathrm{KQ}$, Huang $G$, Gao CF, Wang XL, Ma B, Sun LQ, Wei Z: Identification of lung cancer patients by serum protein profiling using surfaceenhanced laser desorption/ionization time-of-flight mass spectrometry. Am J Clin Oncol 2008, 31:133-139.

28. Yang Y, Zhao S, Fan Y, Zhao F, Liu Q, Hu W, Liu D, Fan K, Wang J: Detection and identification of potential biomarkers of non-small cell lung cancer. Technol Cancer Res Treat 2009, 8:455-466.

29. Anderson NL, Anderson NG: The human plasma proteome: history, character, and diagnostic prospects. Mol Cell Proteomics 2002, 1:845-867.

30. Righetti PG, Boschetti E, Lomas L, Citterio A: Protein Equalizer Technology: the quest for a "democratic proteome". Proteomics 2006, 6:3980-3992.

31. Righetti PG, Boschetti E, Monsarrat B: The "Invisible Proteome": How to Capture the Low- abundance Proteins Via Combinatorial Ligand Libraries. Current proteomics 2007, 4:198-208.

32. Righetti PG, Boschetti E: The Proteominer and the Fortyniners: Searching for Gold Nuggets in the Proteomic Arena. Mass Spectrom Rev 2008, 27:596-608

33. Bradford MM: A rapid and sensitive method for the quantitation of microgram quantities of protein utilizing the principle of protein-dye binding. Anal Biochem 1976, 72:248-254.
34. Breiman L, Friedman JH, Olshen RA, Stone CJ: Classification and regression trees. 1 edition. Belmont, CA: Chapman and Hall/CRC; 1984, 384.

35. Molina R, Auge JM, Escudero JM, Marrades R, Vinolas N, Carcereny E, Ramirez J, Filella X: Mucins CA 125, CA 19.9, CA 15.3 and TAG-72.3 as tumor markers in patients with lung cancer: comparison with CYFRA 211, CEA, SCC and NSE. Tumour Biol 2008, 29:371-380.

36. Bellei E, Bergamini S, Monari E, Fantoni LI, Cuoghi A, Ozben T, Tomasi A: High-abundance proteins depletion for serum proteomic analysis: concomitant removal of non-targeted proteins. Amino Acids 2011, 40:145-156.

37. Hartwig S, Czibere A, Kotzka J, Passlack W, Haas R, Eckel J, Lehr S: Combinatorial hexapeptide ligand libraries (ProteoMiner): an innovative fractionation tool for differential quantitative clinical proteomics. Arch Physiol Biochem 2009, 115:155-160.

38. Sihlbom C, Kanmert I, Bahr H, Davidsson P: Evaluation of the combination of bead technology with SELDI-TOF-MS and 2-D DIGE for detection of plasma proteins. J Proteome Res 2008, 7:4191-4198.

39. Roux-Dalvai F, Gonzalez de Peredo A, Simo C, Guerrier L, Bouyssie D, Zanella A, Citterio A, Burlet-Schiltz O, Boschetti E, Righetti PG, Monsarrat B: Extensive analysis of the cytoplasmic proteome of human erythrocytes using the peptide ligand library technology and advanced mass spectrometry. Mol Cell Proteomics 2008, 7:2254-2269.

doi:10.1186/1477-5956-9-55

Cite this article as: Monari et al.: Enriched sera protein profiling for detection of non-small cell lung cancer biomarkers. Proteome Science 2011 9:55.

\section{Submit your next manuscript to BioMed Central and take full advantage of:}

- Convenient online submission

- Thorough peer review

- No space constraints or color figure charges

- Immediate publication on acceptance

- Inclusion in PubMed, CAS, Scopus and Google Scholar

- Research which is freely available for redistribution

Submit your manuscript at www.biomedcentral.com/submit
Biomed Central 